\title{
Optimalisasi Pertumbuhan Bayi dengan Baby Massage and Spa
}

\author{
Yusari Asih ${ }^{1}$, I Gusti Ayu Mirah WS ${ }^{2}$ \\ Jurusan Kebidanan, Politeknik Kesehatan Tanjung Karang, Indonesia \\ Email: yusariasih@ poltekkes-tjk.ac.id
}

\begin{abstract}
Optimizing Growth of Infants with Baby Massage and Spa. Baby Massage and Spa was a traditional effort that uses a holistic approach through comprehensive care using a combination of massage and water therapy methods that are carried out in an integrated manner to balance the body, mind, and feelings. Age 3-6 months is the right time for babies to do massage and spa. The purpose of this study was to determine the effect of baby massage and spa on the growth of infants aged 3-5 months in Pringsewu District in 2018. This study uses a quasiexperimental approach with research design pre and post-test with control group design. The purposive sampling technique was taken with a sample of 30 infants as the intervention group and 30 infants as the control group. Data were processed using computerization and analyzed using the T-Test. The results showed that there were significant differences between body weight, body length and baby head circumference in the pre and post-treatment. There was no significant difference in the average increase in infant weight between babies who were carried out by baby massage and spa with babies who were not carried out by baby massage and spa with p-value 0.116. There is a significant difference in the baby's body length and head circumference performed by baby massage and spa with those not carried out by baby massage and spa with pvalue 0.000 . Baby Massage and Spa has a significant effect on increasing the growth of babies aged 3-5 months.
\end{abstract}

Keywords: Baby Massage and Spa, Baby Growth

\begin{abstract}
Abstrak: Optimalisasi Pertumbuhan Bayi dengan Baby Massage and Spa. Baby Massage and Spa adalah upaya tradisional yang menggunakan pendekatan holistik melalui perawatan menyeluruh dengan menggunakan metode kombinasi antara pijat dan terapi air yang dilakukan secara terpadu untuk menyeimbangkan tubuh, pikiran dan perasaan. Usia 3-6 bulan merupakan saat yang tepat bagi bayi untuk dilakukan massage and spa. Tujuan penelitian ini adalah untuk mengetahui pengaruh baby massage and spa terhadap pertumbuhan bayi usia 3-5 bulan di Kabupaten Pringsewu tahun 2018. Penelitian ini menggunakan pendekatan quasi eksperimen dengan desain penelitian pre and post-test with control group design. Teknik pengambilan sampel purposive sampling dengan jumlah sampel sebanyak 30 bayi sebagai kelompok intervensi dan 30 bayi sebagai kelompok kontrol. Data diolah dengan menggunakan komputerisasi dan dianalisis menggunakan Uji T. Hasil penelitian menunjukkan ada perbedaan yang signifikan antara berat badan, panjang badan dan lingkar kepala bayi pada sebelum intervensi dan sesudah intervensi. Tidak ada perbedaan yang signifikan rerata peningkatan berat badan bayi antara bayi yang dilakukan baby massage and spa dengan bayi yang tidak dilakukan baby massage and spa dengan p-value 0.116. Ada perbedaan yang signifikan panjang badan dan lingkar kepala bayi yang dilakukan baby massage and spa dengan yang tidak dilakukan baby massage and spa dengan $p$ value 0.000. Baby Massage and Spa berpengaruh secara signifikan untuk meningkatkan pertumbuhan bayi usia 3-5 bulan.
\end{abstract}

Kata kunci: Baby Massage and Spa, Pertumbuhan Bayi

\section{PENDAHULUAN}

Periode penting dalam tumbuh kembang anak adalah masa balita karena pada masa ini pertumbuhan dasar akan mempengaruhi dan menentukan pertumbuhan dan perkembangan selanjutnya. Agar anak dapat mencapai pertumbuhan yang optimal, maka diperlukan suatu bentuk perawatan yang lebih intensif diantaranya berupa sentuhan dan stimulasi yang terus-menerus. Salah satunya adalah dengan pemberian massage. Massage merupakan upaya pemenuhan kebutuhan anak baik secara fisik, kasih sayang serta stimulasi mental.

Tanpa disadari ketika memandikan bayi, mengeringkan tubuhnya dengan menggosok punggungnya, atau bermain-main dengan cara 
memijat kakinya, sebenarnya banyak rangsangan yang dilakukan padanya.

Memberikan rangsangan pada bayi memang banyak caranya. Salah satu diantaranya melalui pijatan (stroking). Pijat merupakan bentuk ideal untuk merealisasikannya, sebab saat memijat bayi, ibu "melatih" dirinya untuk lebih mengenal bayinya. Dengan memijat bagian demi bagian tubuh bayi secara lembut, ibu belajar mengenali tubuh dan bahasa tubuh bayinya secara individual. Dari sini akan diketahui pijatan mana yang menyenangkan bagi bayi dan mana yang tidak disukainya. Lama-lama kita akan menjadi lebih terampil dan percaya diri dalam mengurus bayi.

Di kalangan masyarakat Indonesia, ilmu pijat bayi tradisional sudah lama dikenal, dan sampai saat ini di daerah-daerah masih sering dilakukan oleh dukun pijat bayi. Ilmu pijat bayi umumnya mudah dipelajari dengan beberapa kali latihan dan orang tua akan mahir melakukannya. Selain itu pijat bayi juga mudah karena hanya menggunakan minyak (baby oil). badan biasa, dan berat badan sekarang (BBS). Perubahan tersebut penting dicatat untuk mengetahui apakah seseorang mempunyai resiko mengalami malnutrisi (Arisman, 2010).

Penelitian tentang pengaruh pijat bayi terhadap kenaikan berat badan bayi memperoleh hasil bahwa pada kelompok kontrol kenaikan berat badan sebesar $6,16 \%$ pada bayi yang tidak dipijat sedangkan pada kelompok yang dipijat 9,44\% (Dasuki, 2003). Sedangkan pelayanan SPA merupakan bagian dari upaya pelayanan kesehatan tradisional yang sekaligus sebagai upaya pelestarian budaya/pusaka nusantara. SPA merupakan suatu singkatan kata dari bahasa latin yang berasal dari kata Solus Per Aqua (Solus=Pengobatan atau Perawatan, Per=Dengan dan Aqua=Air).

Berdasarkan arti tersebut maka dapat dikatakan bahwa spa adalah suatu sistem pengobatan atau perawatan dengan air atau dalam bahasa Inggris dikenal sebagai Hydroterapi Menurut Permenkes No.1205/Menkes/X/2004, spa merupakan upaya tradisional yang keluarga dan bangsa. Setiap orang tua mengharapkaperawatan menyeluruh dengan menggunakan anaknya dapat tumbuh dan berkembang secarmetode kombinasi antara hydrotherapi (terapi optimal sehingga dapat menjadi sumber dayair) dan massage (pijat) yang dilakukan secara manusia yang berkualitas dan tangguh. Tercapainyđerpadu untuk meyeimbangkan tubuh, pikiran pertumbuhan dan perkembangan yang optimakerta perasaan. Usia 3-6 bulan merupakan saat merupakan hasil interaksi berbagai faktor yang salingang tepat bagi bayi untuk mengenal kolam berkaitan, yaitu faktor genetik, lingkungan, perilakurenang. Hal ini dikarenakan refleks akuatiknya dan rangsangan atau stimulasi yang berguna (Dasukibelum menghilang (kemampuan menarik nafas 2003).

Berat badan merupakan ukuran antopometri yang terpenting dan paling sering digunakan pada bayi baru lahir. Pengukuran berat badan merupakan pengukuran yang terpenting dalam memeriksa bayi atau balita (Maryunani, 2010).

Berdasarkan data laporan dari Puskesmas tahun 2015 dari 30.342 balita ditimbang terdapat 25.221 yang berat badannya naik $(83,33 \%)$. Ditemukan balita dengan grafik berat badan di bawah garis merah yaitu $220(0.06 \%)$, angka ini menurun dibandingkan tahun 2014 yaitu 346 $(1.06 \%)$ dari 30.698 balita ditimbang. Juga terdapat kasus gizi buruk sebanyak 9 kasus. Angka ini meningkat dibandingkan pada tahun 2014 yaitu sebanyak 5 kasus (Dinas Kesehatan Pringsewu, 2014; 2015).

Penyebab terjadinya penurunan berat badan pada bayi disebabkan oleh banyak faktor, antara lain kurangnya asupan nutrisi yang tidak seimbang, pemberian ASI yang tidak tercukupi, gangguan kesehatan, serta masa pertumbuhan. Perubahan berat badan sering dikaitkan dengan berat badan ideal, berat badan normal, berat sebelum menyentuh air), bayi 4 juga mempunyai naluri mengapung dan menyelam yang mencegahnya menelan air saat berada di dalam air.

Berdasarkan penjelasan di atas, penulis tertarik untuk melakukan penelitian untuk mengetahui pengaruh baby massage and spa terhadap pertumbuhan bayi usia 3-5 bulan di Kabupaten Pringsewu tahun 2018.

\section{METODE}

Penelitian ini adalah penelitian kuantitatif menggunakan desain penelitian eksperimen (Arikunto, 2003, 272), dengan rancangan pre and post-test with control group design. Penelitian ini dibagi menjadi dua kelompok, yaitu kelompok intervensi dan kelompok kontrol. Kelompok pertama akan diberikan perlakuan baby massage and spa (Kelompok eksperimen) dengan frekuensi seminggu sekali selama 1 bulan dan kelompok kedua tidak dilakukan baby massage and spa (kelompok kontrol), namun pemilahan kelompok tersebut tidak menggunakan 
penempatan secara acak, dengan rancangan pretest dan post-test design untuk membandingkan objek penelitian dan mengukur tingkat perubahan yang terjadi sebagai hasil dari perlakuan.

Penelitian ini dilaksanakan mulai Maret s.d Desember 2018, di 3G Baby Spa Pringsewu, dan telah mendapatkan persetujuan etik penelitian (ecthical clearance) dari Komisi Etik Penelitian Kesehatan Politeknik Kesehatan Tanjung Karang No. 159/EC/KEP-TJK/VI/2018.

\section{HASIL}

Penelitian ini merupakan penelitian eksperimen. Data penelitian terdiri dari pertumbuhan bayi yang terdiri dari hasil sebelum dan sesudah treatment setelah dilakukan baby massage and spa pada kelompok eksperimen dan tidak dilakukan baby massage and spa pada kelompok kontrol. Analisis dilakukan terhadap setiap variabel dari hasil penelitian yang menghasilkan distribusi dan frekuensi setiap variabel terhadap 60 responden berdasarkan sumber data primer di 3G Baby Spa, Pringsewu.

Hasil analisis univariat variabel penelitian pengaruh Baby massage and spa terhadap Pertumbuhan bayi usia 3-5 bulan adalah sebagai berikut:

Tabel 1. Distribusi Responden Berdasarkan Jenis Kelamin dan Usia

\begin{tabular}{lcc}
\hline \multicolumn{1}{c}{ Variabel } & Jumlah & Persen \\
\hline Jenis Kelamin & & \\
\hline Laki-laki & 35 & 58.3 \\
Perempuan & 25 & 41.7 \\
\hline Usia Bayi & & \\
\hline 3 bulan & 24 & 40 \\
4 bulan & 20 & 33.3 \\
5 bulan & 16 & 26.7 \\
\hline
\end{tabular}

Berdasarkan Tabel 1, dapat diketahui bahwa frekuensi terbanyak bayi berjenis kelamin laki-laki yaitu 58,3\% dan Usia 3 bulan sebanyak $40 \%$.

Jenis data kelompok pada penelitian ini adalah kelompok independen yaitu pertumbuhan bayi pada kelompok yang diberikan treatment baby massage and spa independen (tidak tergantung) dengan pertumbuhan bayi pada kelompok yang tidak diberikan treatment baby massage and spa. Namun demikian, data kedua kelompok dapat dikatakan dependen/pasangan karena kelompok data yang dibandingkan datanya saling memiliki ketergantungan, yaitu data pertumbuhan bayi sebelum dan sesudah diberikan treatment baby massage and spa berasal dari subyek yang sama (data sesudah treatment dependen/tergantung dengan data sebelum treatment). Berdasarkan karakteristik data tersebut, maka dilakukan dua jenis uji beda dua mean yaitu uji beda mean independen (Uji T independent) dan uji beda dependen (Uji T dependent).

\section{Uji T Independent}

Tujuan uji $\mathrm{T}$ Independent adalah untuk mengetahui perbedaan mean dua kelompok data independent dengan syarat yang telah dipenuhi yaitu data berdistribusi normal/simetris, kedua kelompok data independen, dan variabel yang dihubungkan berbentuk numerik dan kategorik (ket: variabel katagorik hanya dengan dua kelompok).

Prinsip pengujian dua mean adalah melihat perbedaan variasi kedua kelompok data adalah homogen. Oleh karena dalam penelitian ini varian kedua kelompok antara yang dilakukan baby massage and spa dan kelompok kontrol yang diuji sama. Uji beda dua mean dilakukan dengan menggunakan uji $\mathrm{T}$ ( $\mathrm{T}$ Test).

Tabel 2. Pengaruh Baby massage and spa terhadap Pertumbuhan Bayi Usia 3-5 bulan

\begin{tabular}{|c|c|c|c|c|c|c|}
\hline Variabel & Baby massage and spa & $\mathbf{n}$ & Mean & $\begin{array}{c}\text { Std. } \\
\text { Deviation }\end{array}$ & $\begin{array}{l}\text { Std. Error } \\
\text { Mean }\end{array}$ & $\begin{array}{c}p- \\
\text { value }\end{array}$ \\
\hline BB Bayi Sebelum & Kelompok Eksperimen & 30 & 6506.67 & 786.057 & 143.514 & \multirow[t]{2}{*}{0.781} \\
\hline Treatment & Kelompok Kontrol & 30 & 6573.33 & 1046.483 & 191.061 & \\
\hline BB Bayi Sesudah & Kelompok Eksperimen & 30 & 7323.33 & 738.444 & 134.821 & \multirow{2}{*}{0.116} \\
\hline Treatment & Kelompok Kontrol & 30 & 6940.00 & 1088.371 & 198.708 & \\
\hline PB Bayi sebelum & Kelompok Eksperimen & 30 & 62.37 & 3.178 & 0.580 & \multirow{2}{*}{0.000} \\
\hline Treatment & Kelompok Kontrol & 30 & 58.80 & 2.797 & 0.511 & \\
\hline PB Bayi sesudah & Kelompok Eksperimen & 30 & 63.47 & 3.060 & 0.559 & \multirow{2}{*}{0.000} \\
\hline Treatment & Kelompok Kontrol & 30 & 59.07 & 2.803 & 0.512 & \\
\hline LK Bayi Pre & Kelompok Eksperimen & 30 & 40.97 & 1.586 & 0.290 & \multirow{2}{*}{0.004} \\
\hline Treatment & Kelompok Kontrol & 30 & 39.63 & 1.829 & 0.334 & \\
\hline LK Bayi Post & Kelompok Eksperimen & 30 & 42.07 & 1.680 & 0.307 & \multirow{2}{*}{0.000} \\
\hline Treatment & Kelompok Kontrol & 30 & 39.90 & 1.954 & 0.357 & \\
\hline
\end{tabular}


Pada Tabel tersebut dapat dilihat nilai rerata, standar deviasi dan standar error pertumbuhan bayi untuk masing-masing kelompok. Rerata berat badan bayi yang dilakukan treatment baby massage and spa adalah 7323,33gr dengan standar deviasi 738.444gr, sedangkan untuk bayi yang tidak dilakukan baby massage and spa rerata kadar berat badannya $6940.00 \mathrm{gr}$ dengan standar deviasi 1088.371gr. Hasil uji statistik didapatkan nilai $p=0,116$, berarti pada alpha $5 \%$ terlihat tidak ada perbedaan yang signifikan rerata berat badan bayi antara bayi yang dilakukan baby massage and spa dengan bayi yang tidak dilakukan baby massage and spa.

Rerata panjang badan bayi yang dilakukan treatment baby massage and spa adalah $63.47 \mathrm{~cm}$ dengan standar deviasi $3.060 \mathrm{~cm}$, sedangkan untuk bayi yang tidak dilakukan baby massage and spa rerata panjang badannya 59.07 dengan standar deviasi $2.803 \mathrm{~cm}$. Hasil uji statistik didapatkan nilai $p=0,000$, berarti pada alpha $5 \%$ terlihat ada perbedaan yang signifikan rerata panjang badan bayi antara bayi yang dilakukan baby massage and spa dengan bayi yang tidak dilakukan baby massage and spa.
Rerata lingkar kepala bayi yang dilakukan treatment baby massage and spa adalah $42.07 \mathrm{~cm}$ dengan standar deviasi $1.680 \mathrm{~cm}$, sedangkan untuk bayi yang tidak dilakukan baby massage and spa rerata lingkar kepalanya 39.90 dengan standar deviasi $1.954 \mathrm{~cm}$. Hasil uji statistik didapatkan nilai $p=0,000$, berarti pada alpha $5 \%$ terlihat ada perbedaan yang signifikan rerata lingkar kepala bayi antara bayi yang dilakukan baby massage and spa dengan bayi yang tidak dilakukan baby massage and spa.

\section{Uji T Dependent (Paired Sample)}

Tujuan Uji T Dependent adalah untuk menguji perbedaan mean antara dua kelompok data yang dependen. Apakah ada perbedaan pertumbuhan bayi antara sebelum dan sesudah dilakukan baby massage and spa. Uji ini dilakukan karena kelompok data memenuhi syarat berdistribusi normal, kedua kelompok data dependen/pair, dan jenis variabelnya numerik dan katagorik (dua kelompok).

Distribusi rerata Pertumbuhan Bayi Sebelum dan sesudah treatment baby massage and spa.

\begin{tabular}{|c|c|c|c|c|c|c|}
\hline Variabel & Mean & SD & SE & $\begin{array}{c}\text { Mean } \\
\text { Perbedaan }\end{array}$ & $\begin{array}{c}\text { SD } \\
\text { Perbedaan } \\
\end{array}$ & $p$-value \\
\hline \multicolumn{7}{|l|}{ Berat Badan } \\
\hline Pengukuran I & 6540 & 918.215 & 118.541 & 591.667 & 363.734 & 0.000 \\
\hline Pengukuran II & 7131,67 & 942.138 & 121.630 & & & \\
\hline \multicolumn{7}{|l|}{ Panjang Badan } \\
\hline Pengukuran I & 60.58 & 3.470 & .448 & 0.683 & 0.748 & 0.000 \\
\hline Pengukuran II & 61.27 & 3.659 & .472 & & & \\
\hline \multicolumn{7}{|l|}{ Lingkar Kepala } \\
\hline Pengukuran I & 40.30 & 1.825 & .236 & 0.683 & 0.792 & 0.000 \\
\hline Pengukuran II & 40.98 & 2.111 & .273 & & & \\
\hline
\end{tabular}

Tabel tersebut menunjukkan Rerata berat badan bayi pada pengukuran pertama adalah 6540gr dengan standar deviasi 918,215. Pada pengukuran kedua didapat rerata berat badan bayi adalah $7131,67 \mathrm{gr}$ dengan standar deviasi 942,138 gr. Terlihat nilai mean perbedaan antara pengukuran pertama dan kedua adalah 0,591 dengan standar deviasi 363,74. hasil uji statistik didapatkan nilai 0,000 maka dapat disimpulkan ada perbedaan yang signifikan antara berat badan bayi pengukuran pertama dan kedua.

Rerata Panjang badan bayi pada pengukuran pertama adalah $60.58 \mathrm{~cm}$ dengan standar deviasi 3.470. Pada pengukuran kedua didapat rerata panjang badan bayi adalah $61.27 \mathrm{~cm}$ dengan standar deviasi $3.659 \mathrm{~cm}$. Terlihat nilai mean perbedaan antara pengukuran pertama dan kedua adalah 0.683 dengan standar deviasi 0.748 . Hasil uji statistik didapatkan nilai 0,000 maka dapat disimpulkan ada perbedaan yang signifikan antara panjang badan bayi pengukuran pertama dan kedua.

Rerata lingkar kepala bayi pada pengukuran pertama adalah $40.30 \mathrm{~cm}$ dengan standar deviasi 1.825. Pada pengukuran kedua didapat rerata panjang lingkar kepala bayi adalah $40.98 \mathrm{~cm}$ dengan standar deviasi $2.111 \mathrm{~cm}$. Terlihat nilai mean perbedaan antara pengukuran pertama dan kedua adalah 0.683 dengan standar deviasi 0.792 . Hasil uji statistik didapatkan nilai 0,000 maka dapat disimpulkan ada perbedaan yang signifikan antara lingkar kepala bayi pengukuran pertama dan kedua. 


\section{PEMBAHASAN}

\section{Karakteristik Responden Berdasarkan Jenis Kelamin}

Responden yang melakukan baby spa berjenis kelamin laki-laki yaitu 35 responden $(58,3 \%)$, sedangkan perempuan hanya 25 responden $(51,7 \%)$. Hal ini dapat dilihat bahwa anak yang berjenis kelamin laki laki lebih banyak dibandingkan anak berjenis kelamin perempuan yang melakukan baby spa.

Menurut Tim Galenia MCC (2014) mengatakan bahwa baik anak berjenis laki-laki maupun perempuan sama-sama membutuhkan pertumbuhan fisik yang optimal. Tetapi pertumbuhan fisik anak berjenis kelamin laki-laki pertumbuhan fisiknya lebih lambat dibandingkan dengan anak berjenis kelamin perempuan.

Soetjiningsih (2015) mengatakan pacu tumbuh (growth spurt) anak perempuan dimulai lebih cepat dibandingkan anak laki-laki, tetapi pertumbuhan anak perempuan lebih cepat berhenti daripada anak laki-laki.

Dari uraian di atas dapat dilihat bahwa pacu tumbuh (growth spurt) anak laki-laki lebih lambat. Hal ini merupakan salah satu alasan beberapa orang tua dari anak berjenis laki-laki untuk memberikan perawatan lebih untuk menstimulus pertumbuhan fisik anak agar tumbuh secara optimal sehingga dalam pertumbuhan fisik yang lebih lambat daripada perempuan nanti tidak terjadi hambatan seperti tinggi badan menjadi pendek dan berat bedan kurang.

\section{Karakteristik Responden Berdasarkan Usia}

Usia bayi yang paling banyak mengikuti treatment baby massage and spa berusia 3 bulan yaitu 24 (40\%), usia 4 bulan sebanyak 20 bayi, dan usia 5 bulan sebanyak 16 bayi.

Hal ini sesuai dengan teori bahwa usia 3-6 bulan merupakan usia yang tepat untuk memulai baby massage and spa. Setelah usia 3 bulan neck control sudah baik sehingga kepala bayi dapat tegak. Bayi memiliki sepasang refleks yang dapat membuat mereka berenang dengan baik yaitu refleks menyelam (dive reflect) dan refleks berenang (swim reflect). Ketika refleks berenang dan menyelam keduanya terlibat, bayi dapat terlihat seperti perenang alami (Maharani, 2009).

\section{Pertumbuhan Bayi}

Hasil penelitian menujukan bahwa baby massage and spa berpengaruh terhadap pertumbuhan bayi, yang meliputi berat badan, panjang badan dan lingkar kepala di Klinik 3G Baby Spa Pringsewu dengan pvalue 0,000 . Keputusan uji statistik diterima jika $p<0.05$. Maka dapat disimpulkan ada pengaruh yang signifikan antara baby massage and spa dengan pertumbuhan bayi usia 3-5 bulan di Klinik 3G Baby Spa Pringsewu.

Hal ini sesuai dengan penelitian yang dilakukan oleh Tri dkk, yang menunjukan bahwa uji mann whitney didapatkan p-value sebesar $0,01 \quad(p<0,05)$ sehingga pemberian terapi pijat berpengaruh terhadap peningkatan berat badan sesuai dengan hasil penelitian Tri et al (2014) bahwa Baby Spa berpengaruh terhadap peningkatan berat badan bayi.

Pertumbuhan fisik merupakan aspek kesehatan yang sangat penting diperhatikan sejak dini, karena secara estetika anak yang memiliki pertumbuhan fisik yang normal akan lebih baik dibanding anak yang pertumbuhan fisiknya tifdak normal. Untuk mendekteksi perubahan yang terjadi pada anak, para orang tua harus selalu memonitor setiap tahapan pertumbuhan anak dengan cermat. Hal ini di tandai dengan banyaknya orang tua yang memberikan stimulasi kepada anaknya dengan memanfaatkan jasa baby spa agar pertumbuhan fisik anaknya mengalami pertumbuhan yang normal (Fida \& Maya, 2012).

Peningkatan berat badan, panjang badan dan lingkar kepala merupakan indikator untuk menilai pertumbuhan bayi. Pertumbuhan bayi pada umumnya dimulai pada hari ke 7-10 setelah kelahiran. Pada saat bayi berusia 4-5 bulan sudah mencapai dua kali lipat berat badan lahir. Setelah 4-5 bulan pertama pertumbuhan sedikit melambat namun masih jauh lebih cepat dibanding pertumbuhan pada usia selanjutnya.

Hasil penelitian yang sudah dilakukan bahwa 60 responden yang melakukan baby massage and spa sebanyak 30 responden (50\%) mengalami pertumbuhan fisik (BB, PB dan LK) secara normal. Hal ini karena pemberian stimulasi dengan baby massage and spa mempunyai manfaat untuk mengoptimalkan pertumbuhan fisik pada anak (Tim Galenia MCC, 2014). Sedangkan sebanyak 11 responden $(28,9 \%)$ mengalami pertumbuhan fisik (BB dan TB) secara tidak normal.

Petumbuhan fisik dipengaruhi oleh faktor internal dan eksternal. Selain pemberian stimulasi dengan baby spa, namun ada faktor lain yang juga ikut berpangaruh terhadap proses pertumbuhan bayi, misalnya faktor genetik yang merupakan modal dasar dan mempunyai peran utama dalam mencapai hasil akhir proses tumbuh kembang, dan faktor pre-natal yang 
mempengaruhi anak sebelum lahir dan yang terakhir faktor post-natal yang mempengaruhi anak setelah lahir (Soetjiningsih, 2015).

\section{Pengaruh Baby Massage and Spa terhadap Pertumbuhan Bayi Usia 3-5 Bulan}

Berdasarkan hasil uji T Independent dapat dilihat nilai rerata, standar deviasi dan standar error pertumbuhan bayi untuk masing-masing kelompok. Rerata berat badan bayi yang dilakukan treatment baby massage and spa adalah 7323,33gr dengan standar deviasi 738.444gr, sedangkan untuk bayi yang tidak dilakukan baby massage and spa rerata kadar berat badannya $6940.00 \mathrm{gr}$ dengan standar deviasi 1088.371gr. Hasil uji statistik didapatkan nilai $p=0,116$, berarti pada alpha $5 \%$ terlihat tidak ada perbedaan yang signifikan rerata berat badan bayi antara bayi yang dilakukan baby massage and spa dengan bayi yang tidak dilakukan baby massage and spa.

Hal ini menunjukkan bahwa pertumbuhan yang meliputi berat badan, panjang badan dan lingkar kepala pada kelompok intervensi dan kelompok kontrol memiliki kesamaan. Proses tumbuh dan kembang anak mempunyai prinsipprinsip yang saling berkaitan. Terdapat persamaan pola pertumbuhan anak, sehingga pertumbuhan anak bisa diramalkan (IDAI, 2008).

Penimbangan berat badan bayi sebelum dilakukan treatment baby massage and spa rerata 6506.67 pada kelompok eksperimen dan 6573.33 pada kelompok kontrol. Bila dilihat status gizi $\mathrm{BB} / \mathrm{U}$ pada kedua kelompok tersebut berada dalam batas normal.

Rerata berat badan setelah perlakuan adalah 7323.33gr pada kelompok eksperimen dan 6940gr pada kelompok kontrol. Baby massage and spa merupakan salah satu tindakan stimulasi yang diberikan pada bayi untuk melatih kekuatan otot dan kekuatan tubuh, membantu perkembangan sistem pernapasan bayi, relaksasi dan memperbaiki sirkulasi pencernaan. Dengan demikian akan meningkatkan pola asupan nutrisi pada bayi sehingga akan membantu tercapainya pertumbuhan yang optimal.

Rerata panjang badan bayi yang dilakukan treatment baby massage and spa adalah $63.47 \mathrm{~cm}$ dengan standar deviasi $3.060 \mathrm{~cm}$, sedangkan untuk bayi yang tidak dilakukan baby massage and spa rerata kadar berat badannya 59.07 dengan standar deviasi $2.803 \mathrm{~cm}$. Hasil uji statistik didapatkan nilai $p=0,000$, berarti pada alpha 5\% terlihat ada perbedaan yang signifikan rerata panjang badan bayi antara bayi yang dilakukan baby massage and spa dengan bayi yang tidak dilakukan baby massage and spa.

Rerata lingkar kepala bayi yang dilakukan treatment baby massage and spa adalah $42.07 \mathrm{~cm}$ dengan standar deviasi $1.680 \mathrm{~cm}$, sedangkan untuk bayi yang tidak dilakukan baby massage and spa rerata kadar lingkar kepalanya 39.90 dengan standar deviasi $1.954 \mathrm{~cm}$. Hasil uji statistik didapatkan nilai $p=0,000$, berarti pada alpha $5 \%$ terlihat ada perbedaan yang signifikan rerata lingkar kepala bayi antara bayi yang dilakukan baby massage and spa dengan bayi yang tidak dilakukan baby massage and spa

Hasil ini sesuai dengan teori Tim Galenia (2014) bahwa manfaat baby spa adalah mengoptimalkan pertumbuhan fisik anak seperti menjadikan berat badan dan tinggi badan anak menjadi normal sesuai dengan anjuran dari Kementerian Kesehatan dalam tabel pertumbuhan fisik normal. Baby spa juga mempunyai manfaat yang terdiri dari manfaat baby swim (berenang) dan manfaat massage (pijat). Manfaat baby swim itu sendiri yaitu untuk merangsang gerakan motorik pada bayi sehingga otot-otot bayi akan berkembang dengan sangat baik, persendian tubuh akan bekerja secara optimal yang mengakibatkan pertumbuhan badan meningkat secara optimal. Hal ini sesuai teori dari Tim Galenia (2014) mengatakan bahwa manfaat dari baby swim (berenang) itu sendiri merangsang gerakan motorik, pertumbuhan badan meningkat dan tubuhpun menjadi lentur.

Hal ini sesuai dengan penelitian yang dilakukan oleh Profesor Robyn Jourgensen (2007) dalam Roesli (2009) yang menunjukan bahwa anak-anak yang belajar berenang diusia dini memiliki banyak keterampilan dan mencapai titik pertumbuhan yang lebih cepat karena berenang membutuhkan gerakan seluruh otot motorik nya. Berenang secara rutin juga dapat meningkatkan metabolisme tubuh bayi sehingga mempengaruhi nafsu makan bayi.

Apabila metabolisme tubuh bayi terganggu menyebabkan nafsu makan bayi menurun dan jika metabolisme tubuh bayi meningkatkan menyebabkan nafsu makan juga meningkat. Sehingga jika anak berenang secara rutin maka selain meningkatkan pertumbuhan, berenang juga dapat meningkatkan berat badan (Roesli, 2009).

Manfaat massage (pijat) pada bayi yaitu untuk memberi efek stimulasi, relaksasi, melancarkan peredaran darah, meningkatkan daya tahan tubuh dan meningkatkan berat badan. Hal ini sesuai teori Tim Galenia (2014) mengatakan bahwa manfaat dari massage (pijat) itu sendiri melancarkan peredara darah, meningkatkan berat badan, meningkatkan 
pertumbuhan, meningkatkan daya tahan tubuh, meningkatkan konsentrasi bayi dan membuat bayi tidur lelap serta membina ikatan kasih sayang orang tua.

Hasil ini sesuai dengan penelitian yang dilakukan oleh Field dan Scafidi (1986 dan 1990) dalam Riksani (2012) yang menunjukkan bayi yang di massage (pijat) secara rutin selama 15 menit dalam 2 kali dalam seminggu selama 6 bulan mengalami kenaikan berat badan $50 \%$ lebih banyak dari yang tidak dipijat.

Hasil penelitian juga menunjukan 8 responden $(26,6 \%)$ yang tidak melakukan baby massage and spa mengalami pertumbuhan fisik (BB, PB dan Lingkar Kepala) yang sangat baik. Pertumbuhan fisik yang dimaksud dalam penelitian ini seperti pertumbuhan berat badan, Panjang badan dan Lingkar Kepala yang sesuai dengan pertumbuhan seusianya yang telah dibandingkan dengan tabel pertumbuhan fisik normal dari Kemenkes RI (2010). Sedangkan 2 responden yang melakukan baby massage and spa mengalami pertumbuhan fisik (BB, $\mathrm{PB}$ dan LK) tidak normal. Adapun faktor yang dapat mempengaruhi pertumbuhan fisik anak menjadi normal atau tidak normal, bukan hanya dari pemberian stimulasi dengan jasa perawatan baby spa tetapi ada juga dar faktor internal dan faktor eksternal (Roesli, 2008). Faktor tersebut bisa berupa faktor nutrisi, seperti frekuensi pemberian ASI, kualitas ASI maupun fakor pola tidur bayi.

Hal ini juga dikuatkan oleh Marlow (1988) dan Supartini (2004) dalam Fida dan Maya (2012) bahwa faktor internal yang terdiri dari ras dan etnis atau bangsa, keluarga, umur, jenis kelamin, genetik, kelainan kromosom dapat mempengaruhi pertumbuhan fisik dari dalam atau dapat juga diartikan faktor internal adalah faktor yang diturunkan oleh orang tua kepada anak. Selain faktor internal juga faktor eksternal yang terdiri dari faktor pre-natal yaitu faktor yang mempengaruhi pertumbuhan anak sebelum lahir atau dalam kandungan. Faktor pre-natal terdiri dari gizi dan kondisi psikologis ibu, dan faktor post-natal yaitu faktor yang mempengaruhi pertumbuhan anak setelah lahir yang terdiri dari nutrisi, budaya keluarga atau masyarakat, status sosial, ekonomi keluarga, olahraga atau latihan fisik anak, status kesehatan, lingkungan dan stimulasi. Faktor eksternal ini adalah faktor yang mempengaruhi pertumbuhan anak dari luar. Dengan demikian pada bayi yang sudah dilakukan baby spa namun berat badan dan panjang badannya tidak sesuai dengan umurnya hal ini dapat diakibatkan karena karena faktor genetik ataupun faktor nutrisi.

\section{SIMPULAN}

Berdasarkan hasil analisa dan uji statistik, maka dapat disimpulkan sebagai berikut:

1. Rerata berat badan bayi pada pengukuran pertama adalah $6540 \mathrm{gr}$ dengan standar deviasi 918,215. Pada pengukuran kedua didapat rerata berat badan bayi adalah $7131,67 \mathrm{gr}$ dengan standar deviasi 942,138gr. Terlihat nilai mean perbedaan antara pengukuran pertama dan kedua adalah 0,591 dengan standar deviasi 363,74. Hasil uji statistik didapatkan nilai 0,000 maka dapat disimpulkan ada perbedaan yang signifikan antara berat badan bayi pengukuran pertama dan kedua.

2. Rerata Panjang badan bayi pada pengukuran pertama adalah $60.58 \mathrm{~cm}$ dengan standar deviasi 3.470. Pada pengukuran kedua didapat rerata panjang badan bayi adalah $61.27 \mathrm{~cm}$ dengan standar deviasi $3.659 \mathrm{~cm}$. Terlihat nilai mean perbedaan antara pengukuran pertama dan kedua adalah 0.683 dengan standar deviasi 0.748. Hasil uji statistik didapatkan nilai 0,000 maka dapat disimpulkan ada perbedaan yang signifikan antara panjang badan bayi pengukuran pertama dan kedua.

3. Rerata lingkar kepala bayi pada pengukuran pertama adalah $40.30 \mathrm{~cm}$ dengan standar deviasi 1.825. Pada pengukuran kedua didapat rerata panjang lingkar kepala bayi adalah $40.98 \mathrm{~cm}$ dengan standar deviasi $2.111 \mathrm{~cm}$. Terlihat nilai mean perbedaan antara pengukuran pertama dan kedua adalah 0.683 dengan standar deviasi 0.792. Hasil uji statistik didapatkan nilai 0,000 maka dapat disimpulkan ada perbedaan yang signifikan antara lingkar kepala bayi pengukuran pertama dan kedua.

4. Tidak ada perbedaan yang signifikan rerata berat badan bayi antara bayi yang dilakukan baby massage and spa dengan bayi yang tidak dilakukan baby massage and spa dengan $p$ value 0.116 .

5. Ada perbedaan yang signifikan panjang badan bayi yang dilakukan baby massage and spa dengan yang tidak dilakukan baby massage and spa dengan $p$-value 0.000 .

6. Ada perbedaan yang signifikan Lingkar kepala bayi yang dilakukan baby massage and spa dengan yang tidak dilakukan baby massage and spa dengan p-value 0.000 . 


\section{DAFTAR PUSTAKA}

Arisman, M. B. (2010). Buku Ajar Ilmu Gizi Dalam Daur Kehidupan. Edisi-2. Jakarta: EGC.

Dasuki, M. S. (2003). Pengaruh pijat bayi terhadap kenaikan berat badan bayi umur 4 bulan. (Tesis, Universitas Gadjah Mada).

Dinas Kesehatan Pringsewu. (2014). Profil Kesehatan Pringsewu Tahun 2014. Pringsewu.

Dinas Kesehatan Pringsewu. (2015). Profil Kesehatan Pringsewu Tahun 2015. Pringsewu.

Fida \& Maya. (2012). Pengantar Ilmu Kesehatan. Anak. Yogyakarta: D-MEDIKA.

Ikatan Dokter Anak Indonesia (IDAI). (2008). Bedah ASI. Jakarta: FKUI.

Kementrian Kesehatan Republik Indonesia. (2010). Keputusan Mentri Kesehatan Republik

Indonesia 1995/MENKES/SK/XII/2010. Standar Antropometri Penilaian Status Gizi Anak. Diakses tanggal 24 April 2018 dalam situs http://gizi.depkes.go.id/wpcontent/uploads/ 2011/11/buku-skantropometri-2010.pdf
Kementerian Kesehatan Republik Indonesia. (2004). Peraturan Menteri Kesehatan No 1205 tentang Pedoman Persyaratan Pelayanan Kesehatan Pakai Air (SPA). Jakarta.

Maharani, D. (2009). Buku Serba Pintar Perawatan Bayi dan Balita. Yogyakarta: Araska.

Maryunani, A. (2010). Ilmu kesehatan anak dalam kebidanan. Jakarta: Trans Info Media.

Roesli, U. (2008). Pedoman Pijat Bayi. Jakarta: PT. Trubus Agriwidya dan Anggota IKAPI.

Roesli, U. (2009). ASI Panduan Praktis Ibu Menyusui. Yogyakarta: Banyu Media.

Soetijinigsih. (2015). Tumbuh Kembang Anak Edisi 2. Jakarta: EGC.

Tim Galenia MCC. (2014). Home Baby Spa. Jakarta: Penebar Plus.

Tri, dkk. (2014). Pengaruh Terapi Pijat Terhadap Peningkatan Berat Badan Bayi. JOMPSIK, Volume 1 No 2. Oktober 2014. 